\title{
Molecular diversity of Clostridium botulinum and phenotypically similar strains
}

\author{
T. Grenda, E. Kukier, Z. Sieradzki, M. Goldsztejn, K. Kwiatek \\ Department of Hygiene of Animal Feedingstuffs, National Veterinary Research Institute, \\ 24-100 Pulawy, Poland
}

\begin{abstract}
This study was undertaken to examine phenotypic and genetic features of strains preliminary classified as Clostridium botulinum species. The phenotypic characteristics were assessed with different culture media and biochemical tests. The genetic characterization included detection of botulinum toxin genes by PCR and macrorestriction analysis with SmaI, XhoI and SacII by PFGE (Pulsed-field Gel Electrophoresis). Despite similar biochemical properties of all analysed strains, only $47 \%$ of them contained genes determining toxicity specific to $C$. botulinum species. The most valuable differentiation of $C$. botulinum and C. botulinum-like strains was obtained after SmaI digestion. The highest affinity was observed among $C$. botulinum type B profiles which was even up to $100 \%$. It was found $100 \%$ of affinity between $C$. botulinum and C. botulinum-like strains, however, the similarity among $C$. botulinum and $C$. botulinum-like was generally lower than $80 \%$.
\end{abstract}

Key words: Clostridium botulinum, biochemical properties, PCR, PFGE

\section{Introduction}

Clostridium botulinum is a Gram-positive, spore-forming, rod-shaped anaerobic bacterium, widely distributed in soil, sediments of lakes and decaying vegetation. The anaerobe produces the most potent toxins in the environment, botulinum toxins (BoNTs). Eight serotypes (A-H) of $C$. botulinum are recognized on the basis of different antigenic properties of their respective toxins (Dover et al. 2014). Clostridium botulinum strains are divided into four distinct metabolic groups (I-IV) based on biochemical properties (Hatheway 1990, 1995, Saeed 2004). The first group consists of proteolytic $C$. botulinum strains able to produce $\mathrm{A}, \mathrm{B}$, and $\mathrm{F}$ toxins and non-toxigenic $C$. sporogenes. The second group includes $\mathrm{A}, \mathrm{B}, \mathrm{E}$ non
- protelytic C. botulinum toxotypes. The third group consists of proteolytic and non - proteolytic C, D $C$. botulinum toxotypes and also $C$. novyi type A. Group IV consists of $C$. botulinum type $\mathrm{G}$ (also determined as $C$. argentinense in literature), and also $C$. hastiforme and C. subterminale (Suen et al. 1988, Hatheway 1990, 1995, Rosseto et al. 2014). These physiological groups were based on saccharolytic and proteolytic features, alcohol fermentation end products, heat resistance of spores, and ability to grow in the presence of acids, salts and alcohol, growth in different temperatures (Hatheway 1990).

The diversity of the neurotoxin-producing clostridia has been supported by molecular taxonomic studies (Collins and East 1998, Hill and Smith 2013). Further 16S rRNA analyses of the Clostridia con-

Correspondence to: T. Grenda, e-mail: tomasz.grenda@piwet.pulawy.pl 
firmed the classification of $C$. botulinum into four groupings which corresponded to the four mentioned physiological groups (Collins and East 1998). The experiment on $174 C$. botulinum strains conducted by using sequencing analysis of $16 \mathrm{~S}$ rRNA, BoNT genes and by using amplified fragment length polymorphism (AFLP) confirmed the existence of at least four distinct genomic backgrounds, each of which has likely independently acquired BoNT genes through horizontal gene transfer (Collins and East 1998, Hill and Smith 2013). In addition to $C$. botulinum strains, $C$. butyricum and $C$. baratii are known to produce BoNT types $\mathrm{E}$ and $\mathrm{F}$, respectively (Hall et al. 1985, Suen et al. 1988). Because the other BoNT-negative Clostridia species are also classified to the above described groups, this classification based on ability to produce botulinum toxins is inaccurate. Moreover, there are no selective media for isolation of all strains classified to C. botulinum species which complicate the pathogen identification by traditional culture methods (Gryko et al. 1990, Linstrom and Korkeala 2006). The reference method for BoNTs and $C$. botulinum detection according to the Association of the Official Analytical Chemists (AOAC) is the mouse bioassay (Cunniff 1995). It is based on the intraperitoneal mouse injection of supernatant obtained from suspected culture. At the same time, negative controls are conducted. The occurrence of specific, nervous symptoms in animals confirms the $C$. botulinum presence. The variability of phenotypic features among the strains and high probability of toxin gene lost through passages make the mouse bioassay an insufficient tool for a reliable diagnosis of botulism (Gryko et al. 1990). Furthermore, the examination is also labour- and time-consuming, and ethically controversial (Gryko et al. 1990, Lindström and Korkeala 2006). The molecular methods focused on BoNT genes detection have become a supplementary tool to the mouse lethality assay. They also allow to distinguish $C$. botulinum from $C$. botulinum-like strains (Lindström and Korkeala 2006).

The aim of this study was to examine biochemical and genetic diversity of $C$. botulinum and $C$. botulinum-like strains of various origins collected through the last four decades in Poland.

\section{Materials and Methods}

\section{Isolates}

A total of 68 bacterial strains preliminary classified as C. botulinum-like were studied. Previously, along the collection period, these strains have been classified to $C$. botulinum species. Sixty of them were classified to the I metabolic group and another 8 strains to the II metabolic group. Bacteria were obtained from the Sera and Vaccines Manufacturing (SIS BIOMED) Company in Warsaw $(n=26)$ and from the Military Institute of Hygiene and Epidemiology (MIHE) in Warsaw $(n=26)$. Moreover, food and feed isolates $(n=12)$ phenotypically similar to $C$. botulinum species and $C$. botulinum reference strains from National Collection of Type Cultures, type A (NCTC 887), B (NCTC 3815), E (NCTC 8266) and F (NCTC 10281) were analyzed.

\section{Cultural characterization}

The cultural properties of anaerobic bacteria on agar media were evaluated. The strains deposited in Cryobank (Mast Diagnostica, UK) were inoculated on Fastidious Anaerobe Agar and Willis-Hobbs medium. After incubation at $37^{\circ} \mathrm{C}$ for $48 \mathrm{~h}$ in anaerobic conditions, phenotypic properties of analysed strains were evaluated (lipolysis, proteolysis). The lipholytic properties were evaluated by notification of „pearl layer" on the surface of grown colonies which demonstrate the releasing of free fatty acids from the complexes of triacylglycerols from egg yolk (ingredient of the differential media mentioned). The proteolytic abilities were observed as the brightening zones surrounding the colonies obtained on the FAA and Willis-Hobs solid media. The microscopic slides with anaerobe cultures for fresh Gram staining were also prepared.

\section{Mouse bioassay}

The Clostridia strains were examined by using lethal mouse bioassay according to the AOAC protocol (Cunniff 1995). In the examination, 136 laboratory mice were used. For the seroneutralization purposes, polyvalent botulinum antitoxin $\mathrm{ABEF}$ was used (CDC, USA).

\section{Preparation of DNA for PCR analyses}

The DNA was isolated from 3 to 5 characteristic colonies obtained on FAA and Willis-Hobbs surfaces. The extraction process was carried out using commercial set for DNA preparation - Genomic Mini A\&A Biotechnology (Gdynia, Poland) strictly according to protocol supplied by producer. 


\section{Molecular characterization by PCR}

For $C$. botulinum ntnh gene detection, the set of seven primers and TaqMan probe with locked nucleic acids (LNA) bases were used according to Raphael and Andreadis (2007). The description of sequences are included in Table 1. The above set facilitated the amplification of a highly conserved region common for all seven toxotypes occurring in C. botulinum species and encoding nonhemagglutinin component of BoNTs (NTNH) (Raffestin et al. 2004, Raphael and Andreadis 2007). The reaction mixture contained $5 \mu \mathrm{l}$ of DNA template, $4 \mu \mathrm{l}$ of LightCycler TaqMan Master (Roche), $0.7 \mu \mathrm{M}$ of each primer, and $0.24 \mu \mathrm{M}$ of NTNH410 probe. The real-time PCR was performed on the LightCycler 2.0 System (Roche). Following 10 min activation step at $95^{\circ} \mathrm{C}$, reactions were subjected to 40 cycles, consisting of three steps: at $95^{\circ} \mathrm{C}$ for $15 \mathrm{~s}$, at $42^{\circ} \mathrm{C}$ for $15 \mathrm{~s}$, and at $55^{\circ} \mathrm{C}$ for $60 \mathrm{~s}$. Fluorescence data were acquired following the third step of each cycle $\left(55^{\circ} \mathrm{C}\right)$.

For identification of C. botulinum toxotype A, B, $\mathrm{E}$ or $\mathrm{F}$, the set of eight primers was used, according to De Medici et al. (2009). The description of sequences are included in Table 2. It enabled detection of genes encoding particular BoNTs in toxotype A, B, E and F. The reaction mixture contained $5 \mu \mathrm{l}$ of DNA template, $2.5 \mu \mathrm{l}$ of 10xTaq buffer with $\mathrm{KCl}$ (Fermentas), $0.3 \mu \mathrm{M}$ of each primer, $4 \mathrm{mM}$ of $\mathrm{MgCl}_{2}$ (Fermentas), $200 \mu \mathrm{M}$ of dNTP mixture (Fermentas), and $1.25 \mathrm{U}$ of Taq DNA polymerase (Fermentas) and the final volume of reaction mixture was $25 \mu$ l. The mPCR was performed on T1 Thermocycler (Biometra). Following initial denaturation step at $95^{\circ} \mathrm{C}$ for $60 \mathrm{~s}$, reaction was subjected to 27 cycles at $95^{\circ} \mathrm{C}$ for $30 \mathrm{~s}, 53^{\circ} \mathrm{C}$ for 30 $\mathrm{s}$, and $72^{\circ} \mathrm{C}$ for $3 \mathrm{~min}$. The final extension was carried out at $72^{\circ} \mathrm{C}$ for $3 \mathrm{~min}$. The mPCR products were separated by electrophoresis in $2 \%$ agarose gel stained with ethidium bromide, located in 1xTBE buffer (Fermentas) for $1.5 \mathrm{~h}$ under $100 \mathrm{~V}$. Ten $\mu \mathrm{l}$ of reaction mixture and $2 \mu \mathrm{l}$ of loading buffer 6xDNA Loading Dye (Fermentas) were loaded into each well. The molecular weight of the obtained products were determined on the basis of a molecular weight marker - GeneRuler 100bp DNA Ladder Mix (Fermentas). After separation, PCR products were analysed under the UV light transluminator (Vilber-Lourmat).

\section{Biochemical characterization}

The biochemical features of analysed strains were estimated by Rapid ID 32A and API 20A assays (bioMérieux). The Rapid ID 32A and API 20A test strips were read visually and by the autoreader, mini
API (bioMérieux), and its database version 1.3.1. was used. All steps of preparation the biochemical tests were conducted strictly according to descriptions included in protocols supplied by the producer of tests (bioMérieux).

\section{Molecular subtyping by PFGE}

All C. botulinum and C. botulinum-like isolates were typed by PFGE protocol developed according to the procedures described by Hielm et al. (1998), Nevas et al. (2005) and PulseNet PFGE Manual (CDC 2004). Briefly, the strains were cultured in test tubes with tryptone-peptone-glucose-yeast extract broth (TPGY) during $48 \mathrm{~h}$ at $37^{\circ} \mathrm{C}$, under anaerobic conditions. Subsequently, two drops of the culture from the bottom of the probe were spread on the Columbia agar (pancreatic digest of casein $12.0 \mathrm{~g}$, peptic digest of animal tissue $5.0 \mathrm{~g}$, yeast extract $3.5 \mathrm{~g}$, beef extract $3.0 \mathrm{~g}$, corn starch $1.0 \mathrm{~g}$, sodium chloride $5.0 \mathrm{~g}$, agar $13.5 \mathrm{~g}$ ) with $5 \%$ of sheep blood and incubated at $37^{\circ} \mathrm{C}$ for $24 \mathrm{~h}$, under anaerobic conditions. Afterwards, the culture obtained was suspended in $2 \mathrm{ml}$ of PIV buffer (1M NaCl, $10 \mathrm{mM}$ Tris- $\mathrm{HCl}, \mathrm{pH}$ 7.6) with $4 \%$ formaldehyde. Bacterial suspension was then prepared with a density of $7.5 \mathrm{McF}$ with Densimat (BioMerieux). The suspension was centrifuged at $1260 \mathrm{x} \mathrm{g}$ for $10 \mathrm{~min}$ and the supernatant was decanted. The pellet obtained was resuspended in PIV buffer with $4 \%$ of formaldehyde and centrifuged once more. After the second centrifugation the pellet was suspended in $2 \mathrm{ml}$ of TE buffer $(10 \mathrm{mM}$ Tris, $1 \mathrm{mM}$ EDTA, pH 8.0). Subsequently, $60 \mu$ of $0.1 \%$ lysozyme (Oxoid) was added to $240 \mu \mathrm{l}$ of the suspension, and subjected to thermolysis in Thermomixer comfort (Eppendorf) at $37^{\circ} \mathrm{C}$ for $10 \mathrm{~min}$. To $300 \mu \mathrm{l}$ of lysate at $50^{\circ} \mathrm{C}$ was added $1.2 \%$ low melting point agarose (Prona), $1 \%$ sodium dodecyl sulfate (Oxoid) and 0.2 $\mathrm{mg}$ proteinase $\mathrm{K}$ (Fermentas), and the mixture was poured into plug molds. After solidification at $4^{\circ} \mathrm{C}$, the plugs were transferred into $50 \mathrm{ml}$ tubes containing $4 \mathrm{ml}$ Lysis buffer (50 mM Tris, pH 8.0; $50 \mathrm{mM}$ EDTA, $\mathrm{pH} \mathrm{8.0;1 \%} \mathrm{L-laurylosarcosine} \mathrm{sodium} \mathrm{salt)} \mathrm{and} \mathrm{then}$ placed in $37^{\circ} \mathrm{C}$ water bath for $2 \mathrm{~h}$ with gentle shaking. Afterwards, the lysis buffer was removed and plugs were washed twice in redistilled water in $50^{\circ} \mathrm{C}$ water bath for $10 \mathrm{~min}$ with gentle shaking. Then, washings of the plugs were done four times with TE buffer at $50^{\circ} \mathrm{C}$ for $15 \mathrm{~min}$. Then, the plugs were stored in TE buffer at $2-8^{\circ} \mathrm{C}$ or directly digested with restriction enzymes. Three restriction enzymes for $C$. botulinum DNA digestion, SmaI (CCC $\downarrow$ GGG), XhoI

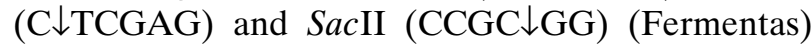
were used. The SmaI and XhoI concentration was 
$2 \mathrm{U} / \mu \mathrm{l}$ and SacII $4 \mathrm{U} / \mu \mathrm{l}$, and the plugs were digested for $4 \mathrm{~h}$

at $37^{\circ} \mathrm{C}$. The restriction fragments of DNA were separated in $1 \%$ agarose in $0.5 \mathrm{X}$ TBE buffer using contour-clamped homogenous electric field (CHEF-DRIII, Bio-Rad). The electrophoresis was conducted for $21 \mathrm{~h}$ at $14^{\circ} \mathrm{C}, 6 \mathrm{~V} / \mathrm{cm}$, with initial and final switching times of $0.4 \mathrm{~s}$ and $40 \mathrm{~s}$. DNA of Salmonella serotype Braenderup strain H9812 was digested with $\mathrm{Xba \textrm {I }}$ (T\CTAGA) and used as molecular weight standard (CDC 2004). Strain H9812 was provided by the National Reference Laboratory for Salmonella at the National Veterinary Research Institute in Pulawy (Poland). Band-based dendrograms were produced by using an unweighted pair-group method using arithmetic averages (UPGMA) with Dice correlation coefficient and $2 \%$ tolerance of band position. The PFGE gels were analysed using the fingerprint analysis software (BioNumerics, Applied Maths, Belgium).

\section{Results}

\section{Cultural characterization}

A total of 68 strains $(100 \%)$ were irregular, cream to pale yellow and gently protuberant on Willis-Hobbs agar. They had a mother-of-pearl layer due to the action of lipase on the fat in the medium. All analysed strains were also surrounded by zone of precipitate. The proteolytic properties exhibited 60 strains (88\%) and it was visible through the zone of illumination around colonies. On FAA agar also irregular, grey to cream-yellow and gently protuberant colonies were observed. Colonies of all C. botulinum strains were covered and surrounded by a thin, pearl layer due to lipase production and lecithinase was also formed by all the strains. The proteolytic properties were difficult to confirm because of pale colour of medium. Microscopic characters revealed Gram-positive, non-motile rods.

\section{Mouse bioassay}

The results of mouse bioassay shown that only 32 $(47 \%)$ of examined strains were able to produce BoNTs. The occurrence of specific, nervous symptoms was observed in mice such as labored abdominal breathing, wasp shape, ruffled fur, weakness of the limbs progressing to total paralysis, gasping for breath (opening of the lower jaw) and death due to respiratory failure.

\section{Molecular characterization by PCR}

Among all 68 strains phenotypically similar to $C$. botulinum species, only 32 strains $(47 \%)$ possessed $n t n h$ and bont genes, which determine BoNT production. The results were compatible with those of mouse bioassay. Six strains $(28 \%)$ were classified as type A, 23 strains as type $\mathrm{B}(72 \%), 2$ strains as type $\mathrm{AB}(6 \%)$ and the single strain was type $\mathrm{F}(3 \%)$.

\section{Biochemical characterization}

According to the Mini API system database, most of C. botulinum $18(56 \%)$ and C. botulinum-like 22 (61\%) strains examined by Rapid ID 32A were classified to $C$. sporogenes species. The percent of identity ranged from 89.4 to $99.9 \%$. Only $4(13 \%)$ of $C$. botulinum strains and $4(12 \%)$ C. botulinum-like strains examined were classified to $C$. botulinum group I species with percent of identity ranging from $84.2 \%$ to $98.1 \%$. Our study demonstrated that 16 $(50 \%)$ of $C$. botulinum isolates were $\alpha$-glucosidase-positive and $18(56 \%)$ produced $\beta$-glucosidase. Among C. botulinum-like strains, $22(61 \%)$ were $\alpha$-glucosidase-positive whilst 17 (48\%) were able to produce $\quad \beta$-glucosidase. $\alpha$-Glucosidase and $\beta$-glucosidase production according to the Mini API system are considered characteristic features for $C$. sporogenes species. We also observed strain of $C$. botulinum type $\mathrm{AB}$ that did not show biochemical characteristics typical of the species according to the Bergey's Manual of Systematic Bacteriology (Cato et al. 1986). It was a single strain type AB, which did not ferment glucose, despite the repeated testing by API 20A. Only one of the strains were was classified to the C. botulinum group II species. In case of the other strains examined by using Rapid ID 32A tests, the Mini API system classification was not acceptable.

The results of API 20A tests were interpreted by using Mini API System. The interpretation shown that $29(90 \%)$ of $C$. botulinum and 31 (85\%) of $C$. botulinum-like strains examined were classified to $C$. botulinum $/ C$. sporogenes species. The identity in this test was estimated at $99 \%$. The identification of the other strains was were not acceptable. This system is invalid in the case of identification of $C$. botulinum group II strains.

\section{Molecular subtyping by PFGE}

A total of 68 isolates were submitted to macrorestriction analysis by PFGE. After SmaI digestion 60 DNA patterns were noted, where 30 strains belonged 


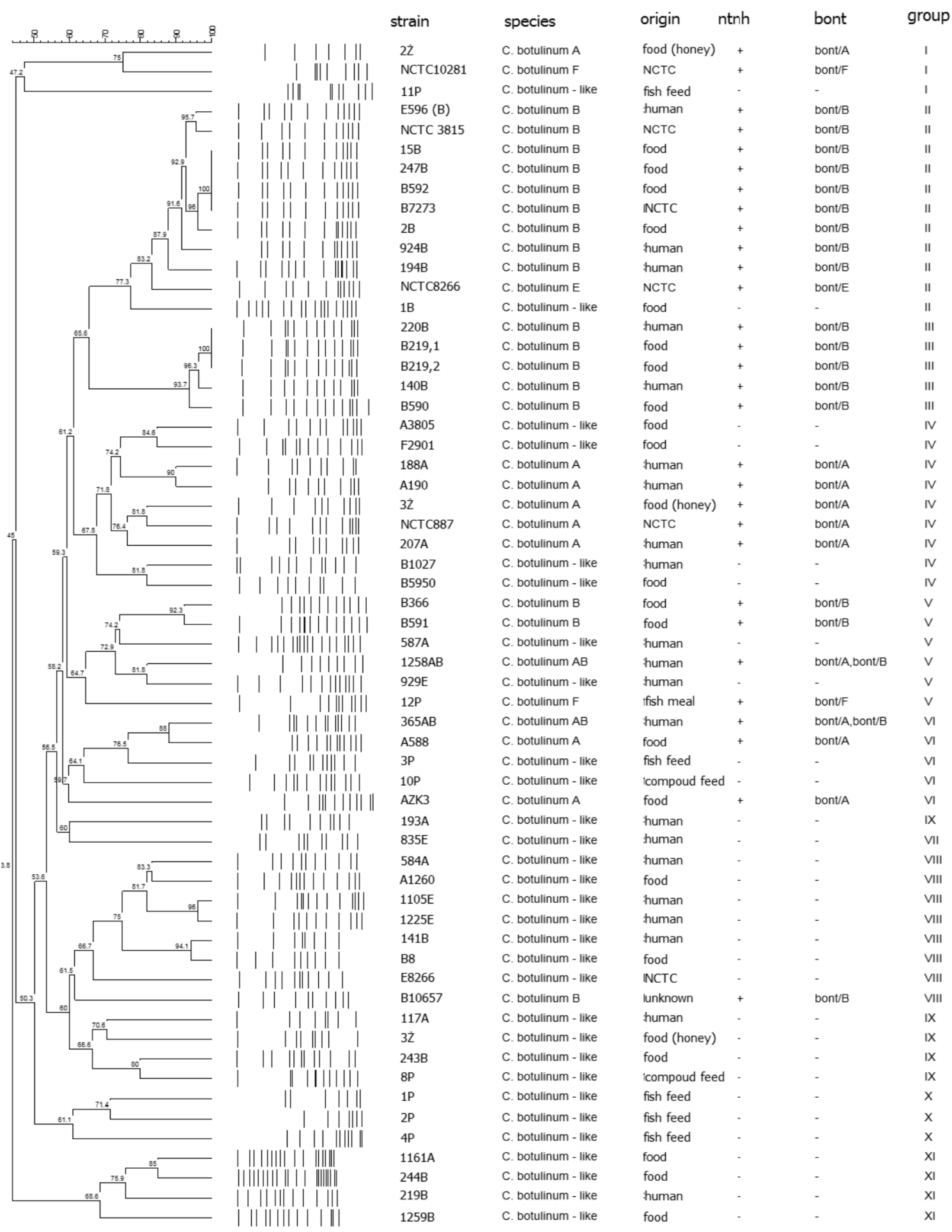

Fig. 1. Smal-PFGE dendrogram based on the Dice coefficient indicating the genetic relatedness of the 60 C. botulinum and $C$. botulinum-like isolates. The scales at the top indicate the similarity indices (in percentage). 


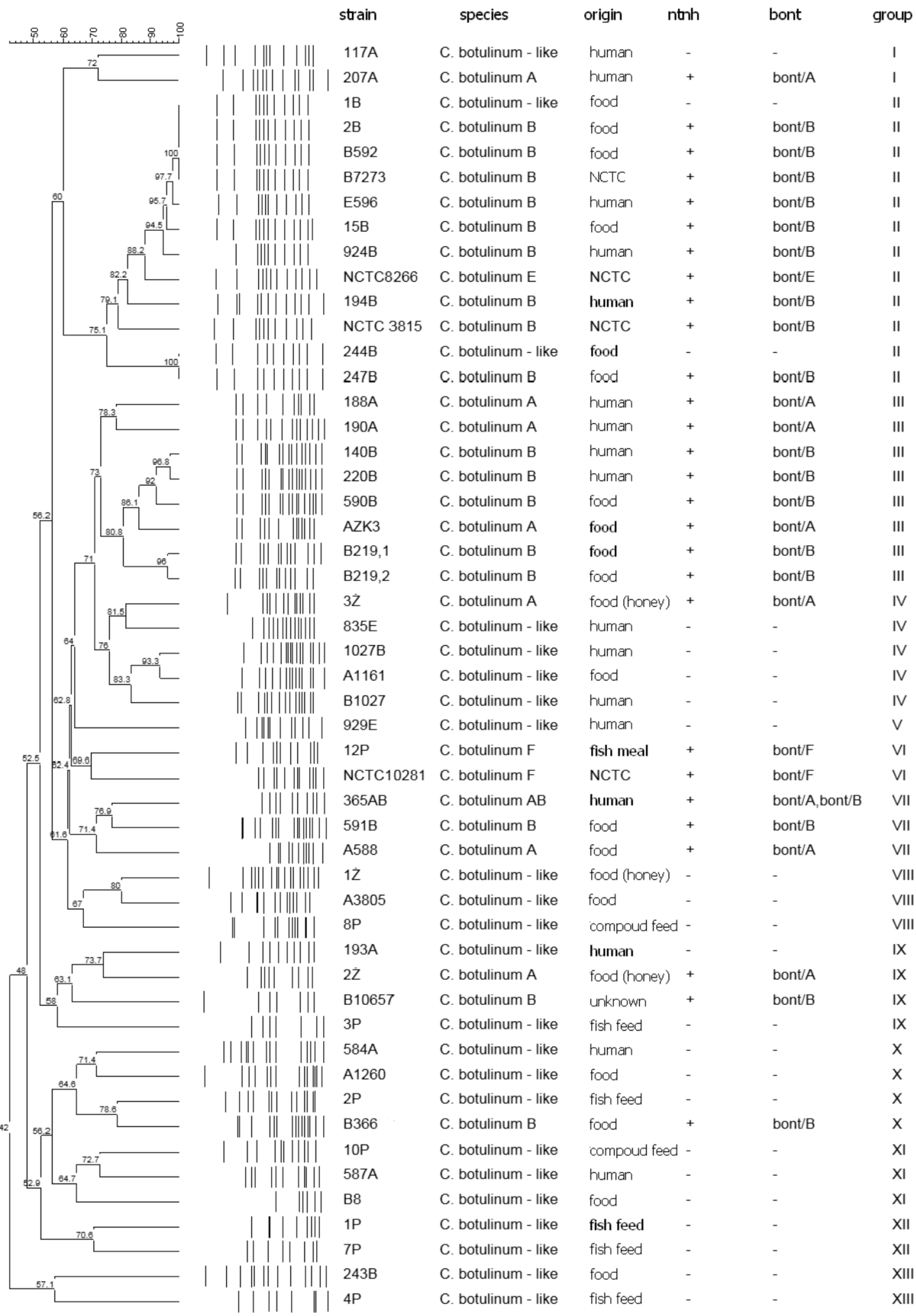

Fig. 2. XhoI-PFGE dendrogram indicating the genetic relatedness of the 51 C. botulinum and C. botulinum-like isolates. 


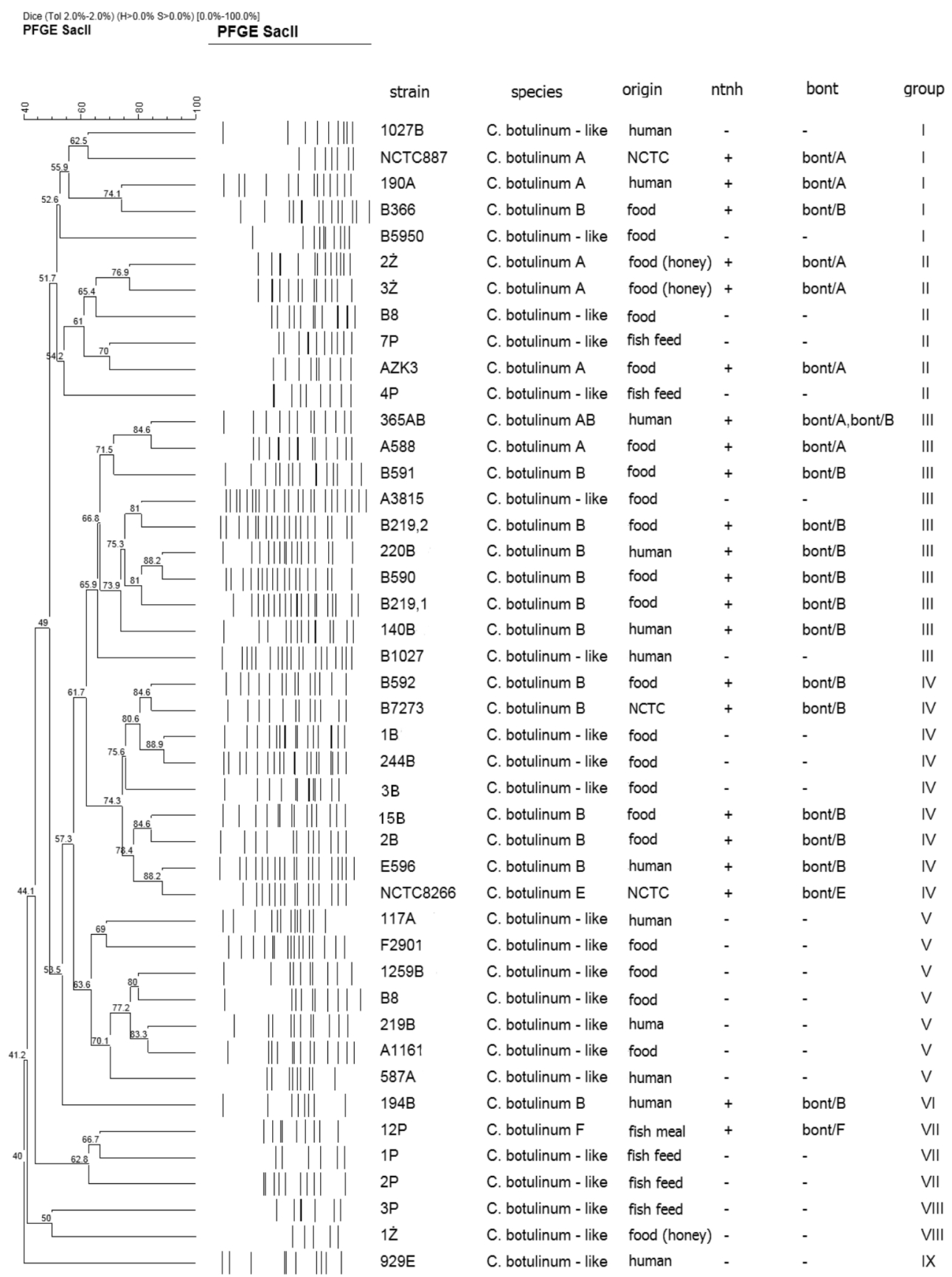

Fig. 3. SacII-PFGE dendrogram indicating the genetic relatedness of the 44 C. botulinum and C. botulinum-like isolates.

to $C$. botulinum and the next 30 isolates were $C$. botulinum-like strains. Clonal relationship among the strains ranged from $44 \%$ to $100 \%$. The restriction patterns had between 7 and 22 bands with approximate sizes of 33 to $1135 \mathrm{~kb}$. However, these 60 isolates could be divided into 11 groups (I - XI) containing between 1 and 11 isolates per group, according to the Dice coefficient of similarity (Fig. 1). The major genetic relatedness was observed in II and III group containing 4 and 3 isolates, respectively, with indistinguishable PFGE patterns (100\% similarity). The af- finity between $C$. botulinum and $C$. botulinum-like strains did not exceed $81.8 \%$.

The XhoI-PFGE profiles $(n=51)$ could be divided into 13 groups (I-XIII) containing between 1 and 12 isolates per group and restriction patterns had between 6 and 17 bands (Fig. 2). There were $28 C$. botulinum and 23 C. botulinum-like patterns. The majority of patterns was represented by one isolate. This group also revealed genetically identical $(100 \%$ similarity) isolates $(n=6)$. It is worth mentioning that, PCR-based identification classified them as $C$. 
botulinum type B $(n=4)$ as well as $C$. botulinum-like $(n=2)$. Clonal relationship in the XhoI-PFGE profiles ranged from $42 \%$ to $100 \%$ and the similarity between C. botulinum and $C$. botulinum-like strains ranged from $58 \%$ to $100 \%$. The most divergent PFGE patterns were in XIII group where similarity amounted to $57.1 \%$.

Based on the size and number of bands, 44 SacII-PFGE patterns and 9 groups (from 1 to 10 isolates) were distinguished, among them 22 isolates were $C$. botulinum and 22 C. botulinum-like. The profiles consisted of 5 to 23 restriction fragments and molecular mass also ranged from 33 to $1135 \mathrm{~kb}$ (Fig 3 ). There were no genetically identical isolates. Clonal relationship ranged from $40 \%$ to $90 \%$ and it was significantly lower than SmaI and XhoI patterns. The similarity between $C$. botulinum and $C$. botulinum-like strains did not exceed $76 \%$. The highest similarity was observed between two $C$. botulinum-like strains and it was $90 \%$. The most divergent PFGE patterns were that of VIII group and the identity was at $50 \%$.

\section{Discussion}

PCR-based methods to overcome difficulties connected with $C$. botulinum identification were used. Only about half of the strains suspected to be $C$. botulinum, revealed the genes specific to the species, despite phenotypic similarities. Among the analyzed C. botulinum isolates type B strains prevailed. Unfortunately, unknown is the exact number of $C$. botulinum strains, that lost their toxicity genes in the course of laboratory isolation, because of panmictic nature of $C$. botulinum species as well as another Clostridium species (Zhou et al. 1993, Johnson and Bradshaw 2001, Sawires and Songer 2006, Bradshaw et al. 2010, Wangroonsarb et al. 2014, McCallum et al. 2015).

The comparison between $C$. botulinum and $C$. botulinum-like strains shown their high biochemical similarity. The common features for the highest number of analyzed strains were glucose and maltose fermentation, and $\alpha$-glucosidase, $\beta$-glucosidase production. The biochemical properties are not sufficient to distinguish $C$. botulinum-like from $C$. botulinum, which was confirmed by other authors. Lindstrom et al. (1999) observed that API 20A test was not able to distinguish between proteolytic $C$. botulinum and $C$. sporogenes. $\alpha$-Glucosidase- and $\beta$-glucosidase-positive $C$. botulinum strains were classified as $C$. sporogenes. The highest efficiency and the most satisfactory effect of macrorestriction PFGE analysis were obtained by using SmaI enzyme. The similar results were obtained by other authors (Hielm et al. 1998, Nevas et al. 2005,
Umeda et al. 2013). Hielm et al. (1998) among 15 restriction enzymes used to the analysis of $C$. botulinum strains obtained from marine environment, recommended SmaI and XhoI. Nevas et al. (2005) recommended using of $S m a I$ enzyme, because differentiation of $\mathrm{F}$ toxin type was possible in the opposition to the usage of XhoI and SacII.

The PFGE revealed heterogeneity of the analysed C. botulinum isolates, however also a high similarity level between the species and $C$. botulinum-like isolates was observed. According to XhoI-PFGE dendrogram, C. botulinum-like $1 \mathrm{~B}$ and 244B from group II were identical to type B C. botulinum 2B, B592, B7273 and 247B, respectively. High relatedness of some analysed strains confirms the fact that the same isolates $(n=11)$ were included in group II by SmaI- as well as XhoI-PFGE, and 8 of them were classified together in group IV after $\mathrm{SacII}$ restriction. It is interesting that among closely related strains of $C$. botulinum type B there was also one strain of type E, which confirms panmictic nature of the anaerobe. The high similarity between $C$. botulinum and $C$. botulinum-like strains was also observed by Carlier et al. (2004) taking into account 16S rDNA sequence. The similarity between $C$. botulinum type B (ATCC 25765) and $C$. botulinum-like strain AIP 355.02 reached the level of $93 \%$. The high percentage of similarity between $C$. botulinum and $C$. botulinum-like strains was also mentioned by Nakamura et al. (1977), Lee and Riemann (1970). They found that homology between this kind of strain sequences was more than $70 \%$.

The isolates numbered 219B, B219.1 and B219.2 as well as $220 \mathrm{~B}$ originated from the same human botulism case and all these strains initially produced BoNT B. Clostridium botulinum-like 219B strain lost genes determining toxicity during passages resulting in distant relatedness with the above mentioned isolates. This deletion decreased isolate relatedness from $100 \%$ to $40 \%$ by SmaI-PFGE and from $81 \%$ to $60 \%$ according to SacII-PFGE. The $100 \%$ relatedness of isolates from single botulism case and the sharp decline of relatedness by SmaI-PFGE confirms a higher utility of SmaI enzyme in C. botulinum macrorestriction analysis. Moreover, digestion of genomic DNA with $S m a$ I resulted in the highest number of readable profiles $(n=60)$ in comparison to the other enzymes, and obtained profiles revealed above 10 restriction fragments.

The obtained similarity levels of $C$. botulinum profiles indicated the differences among particular toxin types. In most cases, A and B toxin types were compared. In the case of type B strains, the similarity achieved the level of $100 \%$ after digestion with SmaI and XhoI, whilst after using of SacII enzyme this level 
was available at $88 \%$. After using $S m a \mathrm{I}$, the similarity between A and B profiles did not exceed 74\%, whilst by using $\mathrm{XhoI} 72 \%$ and $\mathrm{SacII}-74 \%$. The differences among particular profiles were observed by Nevas et al. (2005). For the differentiation of $C$. botulinum strains, they recommended SacII enzyme or its combination with SmaI and XhoI. After digestion of genomic DNA by SacII, they obtained A and B types C. botulinum profiles, the similarity of which did not exceed $80 \%$, whilst among type A strains profiles and type B the similarity reached $100 \%$.

The ability to produce BoNTs by $C$. botulinum strains demands a suitable training for the laboratory staff handling the pathogens from III risk group (Johnson et al. 2005). The $C$. botulinum-like strains, which show high biochemical and genetic similarity to $C$. botulinum could be used for laboratory staff improving trainings purposes within this pathogen identification. Such trainings were recommended by Bradshaw et al. (2010) who conducted the research on non-toxinogenic mutant of $C$. botulinum 62A.

Until now we have not disposed any selective media for growth inhibition of the other anaerobic microflora which compete with $C$. botulinum for nutritional ingredients. Isolation process of this microorganism could be limited by occurrence of the other species with smaller culturing demands e.g. C. perfingens or C. tetani. (Smith 1975, Lindstrom and Korkeala 2006, Kukier and Kwiatek 2010). According to Kukier and Kwiatek (2010) the percentage of feeds contaminated by $C$. perfringens may reach $68 \%$ and $4 \%$ of food of animal origin and occurrence of this microorganism could be inhibitory for the $C$. botulinum growth. The isolation process of this pathogen is also inhibited by the occurrence of anaerobic $C$. botulinum-like bacteria which have not the ability to produce BoNTs. In the literature, toxigenicity loss among $\mathrm{A}, \mathrm{B}, \mathrm{E}$ and $\mathrm{F}$ toxin types has been described (Zhou et al. 1993, Johnson and Bradshaw 2001, Bradshaw et al. 2010). The classification of suspected microorganism to C. botulinum species, based only on biochemical characterization, is not reliable. The PCR and real-time PCR methods described in this study could be used as an excellent tool in $C$. botulinum detection and determination of toxin types of this pathogen, as it was proved by compatible results of MBA test. The most effective genotyping was achieved with the use of SmaI, after treating genomic DNA with this enzyme the PFGE profiles obtained enabled sharp distinguishing between $C$. botulinum and $C$. botulinum-like strains and also between particular toxin types of this pathogen.

As shown above, phenotypic characterization of strain suspected of C. botulinum is not sufficient for a reliable identification of this species and needs gen- etic characterization or the other tests for determining toxigenicity of the suspected strain. According to the authors opinion, the future classification should be based on the expression of genes which determine toxigenicity of suspected strains.

\section{Acknowledgments}

This work was financially supported by the Polish Ministry of Science and High Education (Project No. N N308 563639).

\section{References}

Bradshaw M, Marshall KM, Heap JT, Tepp WH, Minton NP, Johnson EA (2010) Construction of a nontoxigenic Clostridium botulinum strain for food challenge studies. Appl Environ Microbiol 76: 387-393.

Carlier JP, K'ouas G, Lozniewski A, Sirveaux F, Cailloux P, Mory F (2004) Osteosynthesis-associated bone infection caused by a nonproteolytic, nontoxigenic Clostridium botulinum-like strain. J Clin Microbiol 42: 484-486.

Cato EP, George WL, Finegold SM (1986) Genus Clostridium. In: Sneath PHA, Mair NS, Sharpe ME, Holt JG (eds) Bergey's Manual of Systematic Bacteriology, 2nd ed., Wiliams and Wilkins, Baltimore, pp 1141-1200.

Centers for Disease Control and Prevention (CDC) (2004) PulseNetUSA: One-day (24-28h) standardized laboratory protocol for molecular subtyping of Escherichia coli O157:H7, non-typhoidal Salmonella serotypes, and Shigella sonnei by Pulsed Field Gel Electrophoresis (PFGE). http://www.cdc.gov/pulsenet/protocols/ecoli_ salmonella_shigella_protocols.pdf

Collins MD, East AK (1998) Phylogeny and taxonomy of the food-borne pathogen Clostridium botulinum and its neurotoxins. J Appl Microbiol 84: 5-17.

Cunniff P (1995) Official Methods of Analysis of AOAC International, 16th ed., AOAC International, Washington.

De Medici D, Anniballi F, Wyatt GM, Lindstrom M, Messelhausser U, Aldus CF, Delibato E, Korkeala H, Peck MW, Fenicia L (2009) Multiplex PCR for Detection of Botulinum Neurotoxin-Producing Clostridia in Clinical, Food, and Environmental Samples. Appl Environ Microb 20: 6457-6461.

Dover N, Barash JR, Hill KK, Xie G, Arnon SS (2014) Molecular Characterization of a Novel Botulinum Neurotoxin Type H Gene. J Infect Dis 209: 192-202.

Gryko R, Goszczyński D, Lorkiewicz Z (1990) A simple method of detection of toxigenic Clostridium botulinum type B strains. J Microbiol Meth 11: 187-193.

Hall JD, McCroskey LM, Pincomb BJ, Hatheway CL (1985) Isolation of an organism resembling Clostridium barati which produces type $\mathrm{F}$ botulinal toxin from an infant with botulism. J Clin Microbiol 21: 654-655.

Hatheway CL (1990) Toxigenic clostridia. Clin Microbiol Rev 3: 66-98.

Hatheway CL (1995) Botulism: the present status of the disease. Curr Top Microbiol 195: 55-75. 
Hielm S, Bjorkroth J, Hyytia E, Korkeala H (1998) Genomic Analysis of Clostridium botulinum Group II by Pulsed-Field Gel Electrophoresis. Appl Environ Microb 64: 703-708.

Hill KK, Smith TJ (2013) Genetic diversity within Clostridium botulinum serotypes, botulinum neurotoxin gene clusters and toxin subtypes. Curr Top Microbiol Immunol 364: 1-20.

Johnson EA, Bradshaw M (2001) Clostridium botulinum and its neurotoxins: a metabolic and cellular perspective. Toxicon 39: 1703-1722.

Johnson EA, Tepp WH, Bradshaw M, Gilbert RJ, Cook PE, McIntosh EDG (2005) Characterization of Clostridium botulinum strains associated with an infant botulism case in the United Kingdom. Appl Environ Microb 43: 2602-2607.

Kukier E, Kwiatek K (2010) Occurrence of Clostridium perfringens in food chain. B Vet I Pulawy 54: 571-576.

Lee WH, Riemann H (1970) Correlation of toxic and non-toxic strains of Clostridium botulinum by DNA composition and homology. J Gen Microbiol 60: 117-123.

Lindström M, Korkeala H (2006) Laboratory diagnostics of botulism. Clin Microbiol Rev 19: 298-314.

Lindström MK, Jankola HM, Hielm S, Hyytiä EK, Korkeala HJ (1999) Identification of Clostridium botulinum with API 20 A, Rapid ID 32 A and RapID ANA II. FEMS Immunol Med Microbiol 24: 267-274.

McCallum N, Gray TJ, Wang Q, Ng J, Hicks L, Nguyen T, Yuen M, Hill-Cawthorne GA, Sintchenko V (2015) Genomic Epidemiology of Clostridium botulinum Isolates from Temporally Related Cases of Infant Botulism in New South Wales, Australia. J Clin Microbiol. 53: 2846-2853.

Nakamura S, Okado I, Nakashio S, Nishida S (1977) Clostridium sporogenes isolates and their relationship to $C$. botulinum based on deoxyribonucleic acid reassociation. J Gen Microbiol 100: 395-401.

Nevas M, Lindström M, Hielm S, Bjorkroth KJ, Peck MW, Korkeala H (2005) Diversity of proteolytic Clostridium botulinum strains, determined by pulsed-field gel electrophoresis approach. Appl Environ Microb 71: 1311-1317.

Raffestin S, Marvaud JC, Cerrato R, Dupuy B, Popoff MR (2004) Organization and regulation of the neurotoxin genes in Clostridium botulinum and Clostridium tetani. Anaerobe 10: 93-100.

Raphael BH, Anreadis JD (2007) Real-time PCR detection of the nontoxic nonhemagglutinin gene as a rapid screening method for bacterial isolates harboring the botulinum neurotoxin (A-G) gene complex. J Microbiol Meth 71: 343-346.

Rossetto O, Pirazzini M, Montecucco C (2014) Botulinum neurotoxins: genetic, structural and mechanistic insights. Nat Rev Microbiol 12: 535-549.

Saeed EMA (2004) Studies on isolation and identification of Clostridium botulinum investigating field samples specially from equine grass sickness cases. Doctoral dissertation, Faculty of Agriculture, Goettingen University, Goettingen. http://ediss.uni-goettingen.de/bitstream/ handle/11858/00-1735-0000-0006-AEB1-5/saeed.pdf?sequence $=1$

Sawires YS, Songer JG (2006) Clostridium perfringens: insight into virulence evolution and population structure. Anaerobe 12: 23-43.

Smith LD (1975) Inhibition of Clostridium botulinum by strains of Clostridium perfringens isolated from soil. Appl Microbiol 30: 319-323.

Suen JC, Hatheway CL, Steigerwalt AG, Brenner DJ (1988) Genetic confirmation of identities of neurotoxigenic Clostridium baratii and Clostridium butyricum implicated as agents if infant botulism. J Clin Microbiol 26: 2191-2192.

Umeda K, Wada T, Kohda T, Kozaki S (2013) Multi-locus variable number tandem repeat analysis for Clostridium botulinum type B isolates in Japan: comparison with other isolates and genotyping methods. Infect Genet Evol 16: 298-304.

Wangroongsarb P, Kohda T, Jittaprasartsin C, Suthivarakom K, Kamthalang T, Umeda K, Sawanpanyalert P, Kozaki S, Ikuta K (2014) Molecular Characterization of Clostridium botulinum Isolates from Foodborne Outbreaks in Thailand, 2010. PloS One 9(1): e77792. doi:10.1371/journal.pone. 0077792

Zhou Y, Sugiyama H, Johnson EA (1993) Transfer of neurotoxigenicity from Clostridium butyricum to a nontoxigenic Clostridium botulinum type E-like strain. Appl Environ Microbiol 59: 3825-3831. 